\title{
PROFESSORES DE MATEMÁTICA AO TEMPO DO MOVIMENTO DA MATEMÁTICA MODERNA: PERSPECTIVAS DE PESQUISA
}

\section{Mathematics teachers at the time of Modern Mathematics Movement: prospects of research}

Maria Cristina Araújo de Oliveira ${ }^{1}$

\section{Resumo}

Este artigo tem como objetivo levantar questionamentos sobre a formação de professores de Matemática durante o Movimento da Matemática Moderna no Brasil. Esse movimento, que foi uma iniciativa internacional de mudança no ensino de Matemática, ainda deixa marcas nas práticas dos professores atualmente? Que heranças são essas? Com base na leitura de dissertações e teses produzidas no Brasil sobre o MMM, formulamos uma hipótese de que a proposta foi apresentada aos professores das escolas primárias e secundárias de forma bastante "acabada", na medida em que estes eram "treinados" pelos divulgadores do movimento, como GEEM (Grupo de Estudos do Ensino da Matemática) em São Paulo, para levar para sala de aula os novos conteúdos e a nova proposta de trabalho. A existência de realidades tão distintas, por um lado jovens matemáticos e professores de Matemática sendo formados na USP sob forte influência da Matemática produzida nos grupos mais reconhecidos da época como o grupo Bourbaki e por outro lado professores leigos que lecionavam Matemática em várias regiões do Brasil remete-nos a questionamentos de que a apropriação e a prática docente sob a influência do MMM é também muito diversa. As histórias contadas sobre o Movimento da Matemática Moderna no que diz respeito à formação de professores e sua atuação nesse movimento contam muito pouco dos professores que estavam nas escolas e passaram ou não por cursos de aperfeiçoamento (como costumavam chamar na época) e de suas práticas

Palavras-chave: História da Educação Matemática; Movimento da Matemática Moderna; Formação de professores de Matemática.

Doutora em Educação (Currículo), professora do Departamento de Matemática da Pontifícia Universidade Católica de São Paulo, pesquisadora do GHEMAT (www.pucsp.br/ghemat). mcris@pucsp.br 


\section{Abstract}

This article aims to raise questions related to teacher education during the Modem Mathematics Movement in Brazil. Has this movement, which represented an intemational initiative to reform mathematics teaching, left marks that can still be seen in the practice of today's teachers? What heritage is this? On the basis of dissertations and theses produced in Brazil about the MMM, we formulate the hypothesis that the proposal was presented to teachers in primary and secondary schools as a "fait accompli", and that teachers were "trained" by supporters of the movement, such as GEEM(Study Group of Mathematics Teaching) in São Paulo, to cover in their classrooms the new content and the new working proposals. The existence of realities so distinct, on the one hand young mathematicians and mathematics teachers, graduates of USP and under the strong influence of the Mathematics produced in the most famous groups of the epoch, such as the Bourbaki group and on the other hand lay teachers who taught Mathematics in various regions across Brazil, meant that the appropriation of the MMM and the teaching practices that developed under its influence were also very diverse. The stories told about the Modern Mathematics Movement in relation to teacher education and teachers' actuation tell us very little about the teachers who were in the schools and who participated, or not, in the "improvement" courses (as they were called at the time) or about their practices.

Keywords: History of Mathematics Education; Modem Mathematics Movement; Mathematics Teacher Education.

\section{Introdução}

Iniciamos esse texto falando do lugar social de onde parte essa iniciativa de pesquisa. Com uma trajetória profissional determinada pelo trabalho docente no ensino de Matemática há mais de 20 anos, tendo concluído recentemente o doutoramento na área de formação de professores, muitas inquietações permanecem. Interrogamos-nos sobre a continuidade de determinadas práticas docentes que embora sejam questionadas, ainda têm presença marcante no cotidiano das escolas. Poderíamos citar alguns exemplos como a linearidade na apresentação dos conteúdos matemáticos (que oculta a verdadeira complexidade de cada um dos temas e como freqüentemente são vistos separadamente, de maneira estanque, não são explicitadas pelos professores nem tampouco compreendidas pelos alunos, as relações entre os diferentes conteúdos); a supervalorização da álgebra, da resolução de equações em detrimento da geometria, tanto experimental quanto dedutiva e da própria aritmética.

No primeiro semestre de 2005, começamos a participar do GHEMAT (Grupo de História da Educação Matemática) sob a coordenação do professor 
Wagner Valente. O grupo vinha fazendo leituras, discutindo e realizando pesquisas sobre o Movimento da Matemática Moderna (MMM) no Brasil. Um dos projetos desenvolvidos pelo grupo denomina-se "A Matemática Moderna nas escolas do Brasil e de Portugal: estudos históricos comparativos" (VALENTE, 2004). No âmbito desse projeto maior, inserimos um subprojeto sobre a questão da formação de professores durante o Movimento da Matemática Moderna no Brasil e em Portugal.

A partir da leitura de dissertações produzidas no Brasil a respeito desse movimento, formulamos uma hipótese de que a proposta foi apresentada aos professores das escolas primárias e secundárias de forma bastante "acabada", na medida em que estes eram "treinados" pelos divulgadores do movimento, como GEEM (Grupo de Estudos do Ensino da Matemática) em São Paulo, para levar para sala de aula os novos conteúdos e a nova proposta de trabalho.

\section{Os professores de Matemática, durante o MMM, vistos pelas disser- taçóes e teses}

No trabalho de Beatriz D 'Ambrósio (1987), a primeira tese sobre o movimento, a autora analisa que, no Brasil, a reforma pretendia uma proposta que enfatizava 0 aluno como centro do processo de aprendizagem e o papel do professor como guia das descobertas do aluno. No entanto, na prática, prevaleceram a memorização e a ênfase na linguagem, não havendo mudanças em aspectos relativos à concepção de Matemática de alunos e professores.

Alguns trabalhos como o de Soares (2001) apontam a má preparação dos professores para trabalhar com os conteúdos preconizados pelo MMM como responsável pelo fracasso

Nesse trabalho procuramos mostrar que o ponto de vista de muitos professores hoje em dia é que esse fracasso não se deve tanto às idéias da Matemática Moderna mas sim a um conjunto de fatores que levaram a uma distorção das propostas de mudança. A falta de espírito crítico para analisar que as adaptações deveriam ser feitas para cada país, aliadas à má formação dos professores fizeram com que o Movimento tomasse o rumo contrário ao proposto inicialmente. (p. 13).

Diante desse quadro, perguntamo-nos como se dava a formação inicial dos professores de Matemática da época? Qual era a formação dos professores que efetivamente ensinaram a Matemática Moderna? Como era desenvolvida a capacitação dos professores para trabalharem com a Matemática Moderna? 
O primeiro curso superior em Matemática no Brasil foi o da Faculdade de Filosofia, Ciências e Letras da Universidade de São Paulo (USP), que foi fundada em 1934. Até então as escolas de engenharia, do exército e da marinha eram os principais núcleos difusores de Matemática superior no país, quase todos os professores de álgebra superior, cálculo, geometria analítica e descritiva eram engenheiros ou oficiais do exército ou da marinha. (CASTRO, 1999, p. 47, apud SOARES, 2001, p.128).

Nas décadas de 40 e 50 foram realizados na USP alguns cursos com a participação de Matemáticos do grupo Bourbaki, como Jean Dieudonné e André Weil. As idéias defendidas por eles sobre a Matemática Moderna "penetram em nosso sistema de treinamento de jovens matemáticos mais rapidamente do que no de muitos países da Europa e dos Estados Unidos" (NACHBIN, 1996, p. 40 apud SOARES, 2001, p.80).

Na década de 50, tornou-se obrigatório para o magistério no secundário o curso ministrado pelas faculdades de filosofia. Mas pela portaria $n .^{\circ}$ 478/54 de 1954 do MEC estavam habilitados para lecionar Matemática no 1.ํㅜㅇ ciclo também os licenciados em Química, História Natural, Ciências Sociais e Pedagogia. Para os demais ciclos, também os licenciados em Física.

$\mathrm{O}$ abismo existente entre a legislação e a realidade brasileira pode ser exemplificado pela declaração de D' Ambrosio, em depoimento oral, na qual relata que em 1957 "Santa Catarina não tinha nenhum professor licenciado em todo o estado" (BORGES, 2005, p. 138). Nesse mesmo ano, o MEC lançou um programa denominado Campanha de Aperfeiçoamento e Difusão do Ensino Secundário (CADES), que promovia cursos para professores que tinham experiência prática e não tinham formação em curso superior. Tais cursos habilitavam professores leigos com diplomas de licenciatura curta (BORGES, 2005, p.137).

A existência de realidades tão distintas, por um lado jovens matemáticos e professores de Matemática sendo formados na USP sob forte influência da Matemática produzida nos grupos mais reconhecidos da época como o grupo Bourbaki e por outro lado professores leigos que lecionavam Matemática em várias regiões do Brasil remete-nos a questionamentos de que a apropriação e a prática docente sob a influência do MMM é também muito diversa. Ou seja, pesquisar sobre os professores de Matemática ao tempo do Movimento da Matemática Moderna num país de dimensões continentais e tão diverso pressupõe um cuidado em buscar olhares regionais que tragam as particularidades inerentes do contexto social e cultural da população envolvida na tentativa de se fazer uma interpretação a partir de uma descrição densa (GEERTZ, 1989).

Geertz defende um conceito de cultura essencialmente semiótico: "Acreditando como Max Weber, que o homem é um animal amarrado a teias 
de significa dos que ele mesmo teceu, assumo a cultura como sendo essas teias e a sua análise; portanto, não como uma ciência experimental em busca de leis, mas como uma ciência interpretativa, à procura de significado." (GEERTZ, 1989, p.4). Estamos procurando nos aproximar da questão da formação dos professores de Matemática ao tempo do MMM, nos alinhando com 0 conceito de cultura defendido por Geertz. Para ele, no trabalho para construir uma descrição densa de algum fenômeno, consiste o objeto da etnografia, "a etnografia é uma descrição densa" (p.7).

Fazer a etnografia é como tentar ler (no sentido de "construir uma leitura de") um manuscrito estranho, desbotado, cheio de elipses, incoerências, emendas suspeitas e comentários tendenciosos, escrito não com os sinais convencionais do som, mas com exemplos transitórios de comportamento modelado (GEERTZ, 1989, p.7).

Consultando as fichas com as notas de aulas que o professor Ubira$\tan \mathrm{D}^{\prime}$ Ambrosio ${ }^{2}$ escreveu durante o seu curso de bacharelado e licenciatura na USP na década de 50, observamos que o curso de Espaços Vetoriais foi dado no segundo ano, com uma bibliografia muito atual constituída de livros em francês e inglês: Algèbre et Analyse Linéaires (1947), de Andre Lichnerowi$\mathrm{CZ}^{3}$, Finite Dimensional Vector Spaces (1948), Paul R. Halmos e A Survey of Modern Álgebra (1950), de Birkhoff.

Segundo o professor Ubiratan, os conteúdos estudados no curso de espaços vetoriais que teve no $2 .^{\circ}$ ano da graduação não são vistos hoje nem em cursos de pós-graduação pelo grau de complexidade (depoimento oral).

No terceiro ano (1953), Ubiratan teve Álgebra com o professor Jacy Monteiro. Nas fichas constam apontamentos de grupos, anéis, ideais, corpos, espaços vetoriais e extensões algébricas, finalizando com a forma de Jordan de uma matriz.

No período em que Ubiratan freqüentou a graduação "Era freqüente nas aulas de terceiro e quarto ano, às vezes até do segundo ano, a presença de professores do departamento. Muitos desses cursos eram de natureza monográfica, seguindo um texto bem recente, sempre trazendo novidades, e os colegas se beneficiavam dessa atualização permanente" (D’AMBROSIO, 1988, p.57).

Para um professor como Ubiratan D'Ambrosio, que atuou no ensino secundário na década de 50, um dos pontos de insatisfação com o ensino de Matemática da época era em relação ao distanciamento entre a Matemática

2 As fichas pertencem ao APUA (arquivo pessoal Ubiratan D'Ambrosio) que foi doado ao GHEMAT e está em fase de organização.

3 André Lichnerowicz foi um matemático influente durante o Movimento da Matemática Moderna. 
que ele havia estudado em seu curso de formação e a Matemática que lecionava no secundário, como se pode verificar pela citação abaixo:

O que me incomodava era a Matemática que se fazia naquele tempo. E eu ficava chocado com isso, por que eu fiz a faculdade, e tudo aquilo, que eu estudei na faculdade, não tinha nada a ver com as coisas que se fazia no secundário. Bom, aquilo que eu estudava na faculdade era modemo, era Matemática que estava sendo feita pelos pesquisadores atualizados. Nada disso, ..., algum reflexo naquilo que se fazia no secundário (BORGES, 2005, p.143).

Mas acreditamos que esse tipo de insatisfação não fosse da grande maioria dos professores que ensinavam Matemática na época. Segundo Marques (2005), a disciplina estava estabilizada e o clamor por reformas não partiu dos professores que realmente estavam em sala de aula.

Assim começamos a perceber que a Matemática escolar dos tempos prémodernos não estava passando por momentos de turbulência... Não podemos, portanto, de modo algum dizer que os anos 1950 representavam um cenário ideal para uma revolução na disciplina, ou que os professores clamavam por mudanças... (MARQ UES, 2005, p.101).

\section{Os congressos e a formação de professores}

Foram realizados 5 Congressos Nacionais de Ensino da Matemática entre 1955 e 1966. O primeiro deles foi em Salvador, contou com a participação de 94 professores e tinha como objetivo tratar de assuntos diretamente ligados ao ensino de Matemática: os programas, o livro de classe, "tendências modernas do ensino", aperfeiçoamento dos professores. Foram defendidas várias teses que apontavam quais deveriam ser os verdadeiros objetivos da escola secundária e do ensino de Matemática, e convocavam os professores a refletirem sobre sua prática docente. Nesse congresso, foram aprovadas as seguintes recomendações: aumento da carga horária semanal de Matemática no curso secundário; que os professores fizessem uso com freqüência do método de ensino heurístico, evitando um uso excessivo da abstração teórica e mostrando a conexão entre a Matemática e as outras ciências e sobre o livro de classe ser elaborado de modo a se tornar a "chave da ciência para a vida". (CONGRESSO, 1957, p.37 apud SOARES, 2001, p.68).

O segundo congresso nacional de 1957 ocorreu em Porto Alegre com a participação de 400 professores com os objetivos de discutir sobre o ensino de Matemática por meio de teorias de psicopedagogia, fixar normas para "uma 
boa articulação entre os programas dos diversos níveis de ensino", estudar a influência da Matemática nas demais disciplinas e discutir sobre a formação dos professores de Matemática (CONGRESSO, 1959, p.21). O tema "Matemática Moderna" foi abordado nas teses de Ubiratan D'Ambrosio e Osvaldo Sangiorgi, ambos de São Paulo, Jorge Emmanuel Ferreira do Rio de Janeiro e de Martha Maria de Sousa Dantas da Bahia.

Ao final desse congresso, foi aprovado que a inovação do ensino de Matemática no secundário se daria por meio do professor, que deveriam ser oferecidos a eles cursos de aperfeiçoamento e que haveria a elaboração de um programa reformulado em acordo com o progresso tecnológico da época (VITTI, 1998, p.144).

Em 1959 ocorreu o III Congresso Nacional no Rio de Janeiro com a participação de cerca de 500 professores de Matemática. Esse congresso foi patrocinado pela CADES e teve como objetivo estudar problemas do ensino de Matemática (no primário, secundário, comercial, industrial e normal).

Nesse congresso, a "Matemática Moderna" aparece em 3 importantes resoluções que foram aprovadas ao final. Recomendou-se que fossem ministrados cursos de aperfeiçoamento para professores do ensino secundário, de preparação à Matemática Moderna (Teoria dos Conjuntos ou Álgebra Moderna). Discutiram-se sugestões de que algumas escolas desenvolvessem pesquisas experimentais de implantação da Matemática Moderna no ensino e que os resultados fossem discutidos no IV Congresso. Foi também discutida a necessidade de introdução da Matemática Moderna nas faculdades de Filosofia (BÜRIGO, 1989, p. 49).

Segundo Soares (2001), "Na América do Sul um grande estímulo ao início das reformas do ensino de Matemática foi a realização da Primeira Conferência Interamericana sobre Educação Matemática em Bogotá, na Colômbia, no ano de 1961" (p. 41). Dentre as recomendações elaboradas ao final da conferência, destacamos as relativas à formação inicial e continuada dos professores.

Recomendou-se que a formação dos professores que atuariam no ensino médio ficasse exclusivamente a cargo das universidades e que contasse com a participação e influência de matemáticos (FEHR, 1962, p.183 apud SOARES, 2001, p.42).

Ainda nesta mesma conferência, com relação à formação continuada dos professores, foi proposto intercâmbios com as universidades sob a forma de cursos de aperfeiçoamento. Pediram-se também medidas para melhorar as condições econômicas e sociais dos professores, incentivando a dedicação exclusiva e proporcionando melhores salários.

No Brasil, a legislação estava em acordo com as recomendações da Primeira Conferência Interamericana quanto às exigências da formação do 
professor. Segundo Romanelli (1990), os critérios legais para o exercício do magistério pela Lei de Diretrizes e Bases de 1961 exigiam para o ensino de $1^{0}$ e 2. o graus formação em curso de licenciatura curta (para $5^{\underline{a}}$ a $8^{\underline{a}}$ séries) ou plena (para o 2. grau).

É importante ressaltar que embora a legislação de 1961 já trouxesse a exigência de formação em curso de licenciatura para os professores, pelo menos a partir da 5 . $^{\text {a }}$ série, temos ainda nos dias de hoje, em diferentes Estados do Brasil, professores leigos. O que nos leva a pensar no distanciamento entre a legislação, as recomendações feitas pelos pesquisadores e especialistas e os professores que efetivamente estavam atuando em sala de aula ao tempo do Movimento da Matemática Moderna.

O IV Congresso Nacional que ocorreu em Belém em 1962 tratou de forma mais objetiva a questão da introdução da Matemática Moderna no ensino secundário (SOARES, 2001, p.75). O GEEM teve presença marcante apresentando aulas-demonstração sobre o tratamento moderno de tópicos da Matemática e palestras sobre a introdução da Matemática Moderna na escola secundária. O GEEM também apresentou sua sugestão de Assuntos Mínimos para um Moderno Programa de Matemática para o ginasial e para o colégio, documento que já havia sido aprovado em outros 2 fóruns de discussão no mesmo ano.

O V Congresso Nacional foi em 1966 na cidade de São José dos Campos, em que estiveram presentes cerca de 350 participantes. Foi organizado pelo GEEM e o tema foi Matemática Moderna na escola secundária, articulações com o ensino primário e com o ensino universitário. Para esse congresso, vieram ao Brasil matemáticos de vários países: Marshall Stone, dos EUA; George Papy, da Bélgica; Hector Merklen, do Uruguai e Helmuth Renato Volker, da Argentina.

As sessões foram distribuídas em 3 grupos: um que discutiu problemas da Teoria dos Conjuntos e de Lógica Matemática aplicada ao ensino; outro, para os já iniciados em Matemática Moderna, tratou de tópicos de Álgebra Moderna e Espaços Vetoriais; e o último, de problemas de tratamento moderno da Geometria e Lógica Matemática.

Entre as recomendações aprovadas em cada um dos 5 congressos, há sempre indicações sobre a formação inicial ou continuada dos professores de Matemática. O que nos motiva a querer investigar a repercussão de tais recomendações dentre os professores que efetivamente estavam em sala de aula nos ensinos primário e secundário.

Em 1961, foi fundado o GEEM no estado de São Paulo, muito influenciado por grupos de estudos americanos como o SMSG (School Mathematics Study Group), e teve intensa participação na divulgação das idéias da Matemática Moderna no estado e no Brasil de um modo geral. Esse grupo 
trabalhou com a capacitação de professores de Matemática em relação às reformas propostas pelo MMM. Os professores que participavam dos cursos do GEEM tinham apoio do governo do Estado de São Paulo, que os dispensava de suas atividades regulares nos dias dos cursos.

Além dos cursos para professores do secundário e primário, o GEEM promovia palestras ministradas por professores estrangeiros e teve intensa participação em encontros e congressos nos quais divulgava as idéias da Matemática Moderna.

Para D’Ambrosio (1987), até 1970, os cursos do GEEM consistiam em apresentações formais do conteúdo da Matemática Moderna. A partir de então, chegaram ao Brasil outras tendências da Matemática Moderna, pelos trabalhos de Papy e principalmente de Dienes (no GEEM), que provocaram mudanças de ênfase: do conteúdo para a metodologia. Inicia-se, então, uma divisão no grupo que culmina no encerramento de suas atividades em $1976 \mathrm{e}$ na extinção em 1978 (BÜRIGO 1989).

No Brasil, bem como em diversos países, a implantação da Matemática Moderna nas escolas gerou intensa polêmica e o declínio do movimento veio acompanhado de uma obra que proclamava o Fracasso da Matemática Moderna (Kline 1976). Kline constrói argumentos que se contrapõem aos argumentos defendidos pelo MMM com o objetivo de "corrigir" dificuldades no ensino tradicional da Matemática como a memorização. Assim, o autor questiona que pilares do MMM - abordagem dedutiva (lógica Matemática), rigor, linguagem Matemática - possam efetivamente superar as dificuldades do currículo tradicional.

Na opinião do professor Ubiratan D'Ambrosio, as propostas do GEEM eram muitos formais. Ele avalia que fosse importante trabalhar com os alunos conteúdos "modernos" no sentido de serem próximos ao que se está pesquisando em Matemática (e reforça que mantém essa mesma opinião atualmente propondo a inclusão de temas como pesquisa operacional ou fractais na escola básica), mas que o tratamento dado aos conteúdos não pode ter a mesma rigidez que a perseguida pelos matemáticos (BORGES, 2005, p.180-181). D'Ambrosio menciona também as estratégias adotadas pelo GEEM, que pretendiam mudanças rápidas e de forma homogênea, que não respeitavam as diferenças regionais e entre as escolas (BORGES, 2005, p.182).

No trabalho de Stephan (2000), a autora afirma que

Foi o silêncio, na história da educação, sobre o pensamento e ação dos professores em condição de prática pedagógica, que levou-me a indagar como as reformas, impostas por leis, decretos e normas, são vivenciadas em sala de aula, considerando a prática educacional como locus cultural em permanente movimentação e formatação (p.20). 
Assim como essa autora, acreditamos que "muito pouca voz" foi dada aos que realmente levaram a cabo o ensino segundo os ideais da Matemática Moderna. E nos colocamos algumas questões: os professores não entenderam a proposta do MMM? Não foram "bem preparados"? Ou houve resistência às mudanças propostas por desconsiderarem e até mesmo negarem um saber advindo da prática construída por esses professores?

\section{Conclusões}

Levantamos muitas indagações que ainda precisam ser investigadas com maior profundidade. As histórias contadas sobre o Movimento da Matemática Moderna no que diz respeito à formação de professores e sua atuação nesse movimento contam muito pouco dos professores que estavam nas escolas e passaram ou não por cursos de aperfeiçoamento (como costumavam chamar na época) e de suas práticas. Esse movimento, que foi uma iniciativa internacional de mudança no ensino de Matemática, ainda deixa marcas nas práticas dos professores atualmente? Que heranças são essas?

\section{Referências}

BORGES, Rosimeire Aparecida Soares. A matemática moderna no Brasil: as primeiras experiências e propostas de seu ensino. São Paulo, 2005. Dissertação (mestrado) - Pontifícia Universidade Católica de São Paulo, 2005.

BÜRIGO, Elisabete Zardo. Movimento da matemática moderna no Brasil: estudo da ação e do pensamento de educadores matemáticos nos anos 60. Porto Alegre, RS, 1989. Dissertação (Mestrado) - Universidade Federal do Rio Grande do Sul, 1989.

CERTEAU, Michel de . A operação historiográfica. In:

. A escrita da história. Tradução de Maria de Lourdes Menezes; Rio de Janeiro, RJ: Forense Universitária, 1982. p. 65-119.

D'AMBROSIO, Beatriz Silva. The Dynamics and consequences of the modern mathematics reform movement for Brazilian mathematics education. Thesis (Doctor) - Indiana University, 1987.

D’Ambrosio, Ubiratan. Reminiscências do meu tempo de estudante na Maria Antônia. In: SANTOS, M. C. L. (org). Maria Antônia: uma rua na contramão. São Paulo, SP: Nobel, 1988. 
GEERTZ, Clifford. Ainterpretação das culturas. Rio de Janeiro, RJ: Guanabara Koogan, 1989.

KLINE, Morris. 0 fracasso da matemática moderna. São Paulo,SP: Ibrasa, 1976.

MARQUES, Alex Sandro. Tempos pré-modernos: a matemática escolar nos anos 1950. São Paulo, SP, 2005. Dissertação (Mestrado) - Pontifícia Universidade Católica de São Paulo, 2005.

ROMANELLI, Otaíza de Oliveira. História da Educação no Brasil (1930 / 1973). 25. ed. Petrópolis: Vozes, 1990.

SOARES, Flávia dos Santos. Movimento da matemática moderna no Brasil: avanço ou retrocesso? Rio de Janeiro, RJ, 2001. Dissertação (Mestrado) Pontifícia Universidade Católica do Rio de Janeiro, 2001.

STEPHAN, Ana Maria. Reflexão histórica sobre o movimento da matemática moderna em Juiz de Fora. Juiz de Fora, MG, 2000. Dissertação (mestrado) - Universidade Federal de Juiz de Fora, 2000.

VALENTE, Wagner Rodrigues. A matemática moderna nas escolas do Brasil e de Portugal: estudos históricos comparativos. Projeto de pesquisa. [S. l.:s. n.],2004.

VITTI, Catarina Maria. Movimento da matemática moderna: memória, vaias e aplausos. Piracicaba, SP, 1998. Tese (Doutorado) - Universidade Metodista de Piracicaba, 1998.

Recebido: 09 de fevereiro de 2006 Aprovado: 28 de março de 2006. 